\title{
Molecular detection of Bartonella henselae in 11 Ixodes ricinus ticks extracted from a single cat
}

\author{
Yvonne Regier, Wibke Ballhorn and Volkhard A. J. Kempf
}

\begin{abstract}
Background: Bartonella henselae is a highly prevalent, vector-borne pathogen. Transmission to humans and animals by ticks is discussed controversially. Here, we present a case report, where eleven Ixodes ricinus ticks all harbouring B. henselae DNA were removed from one single cat.

Results: The first feeding tick was tested positive for B. henselae DNA. The cat was also found to be seropositive for anti-B. henselae IgG antibodies (titer 1:640). Bartonella henselae was not cultivatable from cat blood. Ten more feeding ticks removed 7 months later contained also B. henselae DNA. Sequence analysis of the 16SrDNA and the 16S-23S internal transcribed spacer (ITS) region revealed 100\% sequence homology between all ticks. Bartonella adhesin A (badA) and VirBNirD4 type IV secretion system (virB) DNA were also detected in all ticks.

Conclusions: Our results indicate that cats may serve as a reservoir for adult ticks to acquire $B$. henselae. Whether this observation implies an increased threat for human and animal health needs to be resolved.
\end{abstract}

Keywords: Vector-borne infections, Transmission, Zoonosis, BadA, VirB, Feline bartonellosis

\section{Background}

Bartonella henselae is a Gram-negative, facultative intracellular, zoonotic pathogen [1]. In its reservoir host "cat" $B$. henselae causes a long lasting, intraerythrocytic, clinically asymptomatic bacteremia [2, 3]. However, cats may also develop diseases like endocarditis [4] and febrile illness [5]. Prevalence of anti-Bartonella antibodies in cat populations ranges from $0 \%$ in Norway [6] to $71 \%$ in Spain [7]. Immunocompetent humans can be infected with $B$. henselae by cat scratches or bites and may suffer thereafter from cat scratch disease [1], whereas immunocompromised individuals may develop vasoproliferative diseases (bacillary angiomatosis, peliosis hepatis $[8,9])$. Among cats, $B$. henselae is transmitted via cat fleas by contamination of wounds with infected flea feces [10]. Other ectoparasites, e.g. ticks, are also suspect vectors for $B$. henselae [11]. Prevalence of $B$. henselae DNA in Ixodes ricinus varies from $0 \%$ in Finland [12] to $60 \%$ in the Netherlands [13]. Although vector competence of ticks for $B$. henselae

\footnotetext{
* Correspondence: volkhard.kempf@kgu.de

University Hospital, Goethe-University, Institute for Medical Microbiology and Infection Control, Frankfurt am Main, Germany
}

has not been experimentally proven in vivo, an in vitro model employing an artificial feeding system successfully demonstrated transmission of B. henselae by ticks [14]. Furthermore, in a mouse infection model, the vector competence of ticks has been demonstrated for the murine pathogen Bartonella birtlesii [15]. However, discussions about the role of ticks as vectors for $B$. henselae are ongoing [16]. This case report describes the detection of $B$. henselae DNA in 11 ticks removed from one cat with an anti-B. henselae IgG titer of 1:640.

\section{Methods}

\section{Sample drawing}

Feeding ticks were removed from a 7-year-old, male, roaming Norwegian forest cat from Rastatt, Germany $\left(48^{\circ} 51^{\prime} \mathrm{N}, 8^{\circ} 12^{\prime} \mathrm{E}\right)$ and stored at $-20^{\circ} \mathrm{C}$ in separate tubes containing ethanol. As the cat is a roaming cat with access to a rural area, tick contact occurs frequently. The first tick was removed in November 2015 and 10 more ticks were taken between March and June 2016 whenever a tick was detected by the owner. Ticks were identified using standard taxonomic keys (e.g. number of legs, shield, genital orifice [17]). For medical reasons and 
to exclude undiagnosed infections, cat serum was taken in December 2015 by venipuncture of the vena cephalica with a sterile $20 \mathrm{G}$ needle. Blood was collected in a serum tube. After coagulation at room temperature for $40 \mathrm{~min}$ the tube was centrifuged for $10 \mathrm{~min}$ at $4000 \mathrm{rpm}$. Serum supernatant was stored at $-20^{\circ} \mathrm{C}$.

Because of the elevated anti B. henselae-IgG titer from December 2015 and facing the detection of $B$. henselae DNA in all ticks taken from this cat in between, whole blood was taken for medical reasons in September 2016 for a detection attempt of $B$. henselae (by cultivation or PCR methods). To access the vena cephalica, the hair was clipped, the skin disinfected with $70 \%$ ethanol and the vein punctured with a sterile $20 \mathrm{G}$ needle. Blood was collected in sterile tubes containing $10 \mu \mathrm{l}$ of ethylendiaminetetraacetic acid disodium salt solution (SigmaAldrich, Steinheim, Germany) as anticoagulant.

\section{Quality control}

The laboratories of the Institute for Medical Microbiology and Infection Control at the University Hospital of the Goethe University in Frankfurt (Germany) undergo a strict quality control management according to accredited standard operating procedures (laboratory accreditation according to ISO 15189:2007 standards; certificate number D-ML-13102-01-00, valid through January 25th, 2021). There was no increase of Bartonella-positive cases during this study; therefore, the possibility of DNA contamination from non-study sources is highly unlikely.

\section{DNA-extraction from ticks}

Ticks were removed from their storage tubes with a sterile forceps, rinsed once in ethanol and twice in sterile water. After grinding each tick with a disposable sterile mortar and pestle, DNA was extracted with the QIAamp DNA Mini kit (Qiagen, Hilden, Germany) according to the manufacturer's instructions. To prevent DNA cross-contamination, each tick was processed individually by using new forceps, tubes and mortars and pestles. Extraction procedure was verified using specific pathogen-free ticks (Insect Services, Berlin, Germany) in which Bartonella spp. was not detected (data not shown).

\section{Culturing of blood samples}

A hundred $\mu$ l of blood was immediately plated onto Columbia blood agar (BD, Heidelberg, Germany), chocolate agar plates (Oxoid, Wesel, Germany) moreover, $100 \mu \mathrm{l}$ were suspended in fresh, quality-controlled Bartonella-liquidmedium [18]. Due to the limited amount of cat blood, no higher volumes were available for the inoculation of liquid cultures. Bacterial cultivation was performed for 8 weeks at $37{ }^{\circ} \mathrm{C}$ with $5 \% \mathrm{CO}_{2}$ and $95 \%$ humidity. The residual blood was frozen at $-80{ }^{\circ} \mathrm{C}$ overnight, thawed at $37^{\circ} \mathrm{C}$ and plated as described. Once per week (over a total period of 8 weeks), $100 \mu \mathrm{l}$ of the liquid cultures were plated onto CBA plates and incubated as described above. PCR analysis from liquid cultures medium was done after 18 days and after 60 days of incubation, respectively.

\section{DNA extraction from blood and liquid cultures}

DNA from the cat's blood and the liquid cultures was extracted using the DNeasy Blood and Tissue Kit (Qiagen, Hilden, Germany) according to manufacturer's instructions.

\section{Polymerase chain reaction}

A nested PCR for the detection of the Bartonella 16S ribosomal DNA (rDNA) was performed as previously described using the Taq DNA Polymerase-Kit (Invitrogen, Schwerte, Germany) $[19,20]$. Furthermore, a PCR detecting the 16S-23S-rRNA internal transcribed spacer (ITS) region of Bartonella was conducted using the Platinum Taq Polymerase-Kit (Invitrogen, Schwerte, Germany) to distinguish Bartonella species [21]. PCR detection of the Bartonella pathogenicity factors $\operatorname{badA}$ and $\operatorname{vir} B$ was conducted with the Pwo SuperYield DNA Polymerase (Roche, Mannheim, Germany). All PCR primers and annealing temperatures are listed in Table 1. Positive and a negative (water) control were always included. DNA was amplified in a Biometra T3000 thermocycler. Products were separated on an agarose gel, ethidiumbromide-stained and visualized under UV light.

\section{Sequencing and alignment}

16S rDNA and ITS PCR products were sequenced (GATC, Konstanz, Germany) with both, forward and reverse primers. Sequences were checked using Chromas software (Technelysium, Version 2.6, South Brisbane, Australia), aligned and compared to $B$. henselae strain BM1374165 (GenBank: HG969191.1) using Clone Manager Professional Suite version 8 (Scientific and Educational Software, Denver, USA).

\section{Immunofluorescence assay}

Indirect immunofluorescence assay (IIFA) was performed using the Bartonella henselae/ Bartonella quintana (IgG) kit (Euroimmun, Lübeck, Germany) with some modifications. Serum dilution series from 1:20 to 1:2,560 were screened for Bartonella cat IgG antibodies. A 1:100 dilution of Alexa Fluor 488-conjugated AffiniPure Goat AntiCat IgG (Jackson ImmunoResearch laboratories, West Grove, USA) was used as secondary antibody. The test was evaluated as positive when specific fluorescence was detected at a titer of $\geq 1: 64$ [22].

\section{Results}

All ticks were female, adult, half- to fully-engorged and were identified as Ixodes ricinus. One feeding tick, which 
Table 1 Primer designation, sequences and annealing temperatures of the conducted PCRs used for the detection of Bartonella spp. from Ixodes ricinus ticks

\begin{tabular}{|c|c|c|c|c|c|}
\hline Target & Primer designation & Sequence $\left(5^{\prime}-3^{\prime}\right)$ & $\begin{array}{l}\text { Length } \\
\text { (bp) }\end{array}$ & $\begin{array}{l}\text { Annealing } \\
\text { temperature }\left({ }^{\circ} \mathrm{C}\right)\end{array}$ & Reference \\
\hline \multirow[t]{2}{*}{ Bartonella spp. $16 \mathrm{~S}$ rDNA (first round) } & A-proteo primer & AGAGTTTGATC(AC)TGGCTCAGA & \multirow[t]{2}{*}{1,210} & \multirow[t]{2}{*}{$62^{\circ} \mathrm{C}(1 \mathrm{~min})$} & \multirow[t]{2}{*}{ [19] } \\
\hline & r-Alpha-sh primer & GTAGCACGTGTGTAGCCCA & & & \\
\hline \multirow[t]{2}{*}{ Bartonella spp. 165 rDNA (nested PCR) } & Bart & CACTCTITAAGAGTGAGCGGCAA & \multirow[t]{2}{*}{990} & \multirow[t]{2}{*}{$65^{\circ} \mathrm{C}(1 \mathrm{~min})$} & \multirow[t]{2}{*}{ [19] } \\
\hline & $\mathrm{r}-\mathrm{BH}$ & CCCCCTAGAGTGCCCAACCA & & & \\
\hline \multirow[t]{2}{*}{ Bartonella 16S-23S ITS } & $325 \mathrm{~s}$ & CTTCAGATGATGATCCCAAGCCTTCTGGCG & \multirow[t]{2}{*}{489} & \multirow[t]{2}{*}{$68^{\circ} \mathrm{C}(15 \mathrm{~s})$} & \multirow[t]{2}{*}{ [21] } \\
\hline & 1100as & GAACCGACGACCCCCTGCTTGCAAAGCA & & & \\
\hline \multirow[t]{2}{*}{ Bad $A$ head region } & badAf8 & TCGAATCTTGCGCTTACAGGAGC & \multirow[t]{2}{*}{325} & \multirow[t]{2}{*}{$59^{\circ} \mathrm{C}(30 \mathrm{~s})$} & \multirow[t]{2}{*}{ Present study } \\
\hline & BadA_head_reverse & CACCGTCAGTCGACTTCCCT & & & \\
\hline \multirow{2}{*}{$\begin{array}{l}\text { Vir B7 of the VirB/D4-type-IV- } \\
\text { secretion-system }\end{array}$} & VirB7_for & GCTGGAAAACGAAAAAGCAA & \multirow[t]{2}{*}{103} & \multirow[t]{2}{*}{$55^{\circ} \mathrm{C}(30 \mathrm{~s})$} & \multirow[t]{2}{*}{ Present study } \\
\hline & VirB7_rev & ACGCGCAATCTCCATAGTGT & & & \\
\hline
\end{tabular}

was removed from the cat in November 2015, was tested positive for $B$. henselae in $16 \mathrm{~S}$ rDNA PCR analysis. In December 2015, the same cat's serum was screened for anti-Bartonella IgG using an indirect immunofluorescence assay (IIFA), revealing a titer of 1:640 (cut-off: 1:64 [22]). No serum was available from September 2016 for determination of anti-Bartonella IgG. Subsequently, between March and June 2016, ten more feeding ticks were removed from the same cat and tested positive for B. henselae via PCR amplification of $16 \mathrm{~S}$ rDNA, 16S23S-ITS, virB- and $\operatorname{badA}$ (Fig. 1). PCR products of the $16 \mathrm{~S}$ rDNA and ITS were sequenced and alignment showed $100 \%$ sequence homology each between all 11 ticks and also to $B$. henselae strain BM1374165 (Positions: ITS: 1483445-1483766, 16S rDNA: 1484693-1485539) (GenBank: HG969191.1) (see Additional file 1: Figure S1 and Additional file 2: Figure S2). No Bartonella DNA was detected in the cat's blood taken in September 2016 and in six different cultural attempts from continuously incubated liquid cultures. Blood plated on solid media and suspended in liquid media remained negative over an incubation period of 8 weeks.

\section{Discussion}

Bartonella spp. are highly prevalent and are found in ticks all over the world [11]. The sampling site of this study
(Rastatt, Germany) is only $35 \mathrm{~km}$ away from Lembach, France, where a previous study showed highest prevalence of B. henselae in ticks in Europe (38\% in nymphs and $12 \%$ in adult ticks) indicating that there might be an increased prevalence of Bartonella-infected ticks in this area [20]. Cats, especially roaming cats, have a high risk of being infested with ticks and other ectoparasites such as fleas which can harbor or transmit Bartonella spp. and other infectious agents such as Anaplasma spp. [10, 11, 20, 23]. In this case, due to a strict ectoparasite control, no fleas were detected on the cat.

Bartonella adhesin A (BadA) mediates adhesion of Bartonella spp. to endothelial cells and the extracellular matrix proteins [24]. The VirB/VirD4 type IV secretion system (VirB) translocates Bartonella effector proteins (Beps) into endothelial host cells, e.g. inhibiting apoptosis, and inducing a proinflammatory phenotype, which is responsible for the chronicity of the infection and involved in the cell invasion process of Bartonella spp. $[25,26]$. We detected the DNA of badA and virB in all eleven ticks analyzed herein. This indicates that these two Bartonella pathogenicity factors are at least present in the genomes of the detected $B$. henselae and might give clues for estimating the extent of the potential health threat for humans and animals infected with those bacteria.

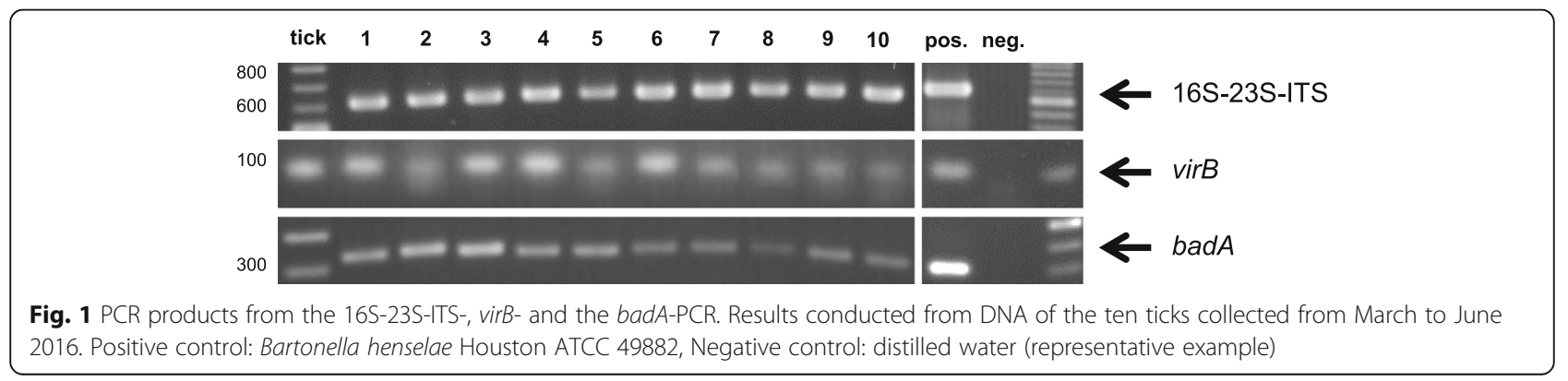


The cat examined in this study was tested seropositive for Bartonella spp. in December 2015 (titer 1:640). Clearance of bacteremia due to presence of anti-Bartonella IgG antibodies could be a possible reason for the negative results of the cultures and PCR from the cat's blood drawn in September 2016. When infected with the murine pathogen $B$. grahamii, immunocompromised mice cleared the resulting intraerythrocytic bacteremia after administration of IgG antibodies obtained from immunocompetent mice [27]. In another study, cats were shown to clear Bartonella bacteremia within 1-8 months after being experimentally inoculated with $B$. henselae subcutaneously [28]. As the cat described herein had a significant serum IgG titer against $B$. henselae, this might indicate that it had already cleared the bacteremia thereby explaining the several negative PCR and cultivation attempts from the peripheral blood. Another possible reason for the lack of viable Bartonella or Bartonella DNA in the blood could be that bacteremia was below the detection limit at the time of blood withdrawal. This hypothesis is supported by a study in which alternating periods of bacteremia were observed in a naturally infected cat over a period of 24 months, with periods of high bacteremia and periods where blood cultures were found to be negative [28].

Furthermore, using a $B$. tribocorum rat infection model, skin dendritic cells have been described to act as vehicles from the primary site of infection (skin) towards the blood stream depending on the function of the Bartonella effector protein E (BepE) [29]. Accordingly, the DNA of all ticks analyzed in our case report contained DNA encoding for the VirB/D4 secretion system (injecting BepE into eukaryotic cells) showing that this machinery is present in our $B$. henselae-genome. This suggests that $B$. henselae might in fact preferentially occupy the dermal niche of cats to enhance vector acquisition by ticks.

The origin of $B$. henselae DNA found in the adult $I$. ricinus ticks of this survey remains speculative. Ticks undergo three life stages as larvae, nymphs and adult ticks. Each life stage takes one single blood meal, providing three possibilities of being infected with $B$. henselae or other infectious agents. We consider infection of the adult ticks examined in this study with $B$. henselae at an earlier life stage unlikely, since sequencing of PCR products showed $100 \%$ sequence homologies for each analyzed (gene) sequence. This points to the possibility, that all ticks became infected by the same host, the cat; however $16 \mathrm{~S}$ and 16S-23S-ITS genes are known to be highly conserved among $B$. henselae isolates. Whether the B. henselae found in ticks were viable remains unclear since we prioritized DNA extraction and therefore did not attempt cultivation of bacteria from ticks.

Engorged, infected, adult hard ticks pose a low risk to human or animal health since they usually only have a single blood meal. However, infection of humans and animals might be possible, since transstadial transmission of Bartonella spp. in I. ricinus occurs when larvae or nymphs feed on infected hosts and progress into the next life stage (larvae to nymph or nymph to adult tick) [14]. Transovarial transmission of Bartonella spp. by ticks is not yet fully resolved. Unengorged larvae were found to harbor Bartonella DNA. Here, vertical transmission of Bartonella spp. might be the explanation for presence of bacteria, if those larvae did not have an undetected blood meal [30]. Furthermore, B. henselae was detected in eggs from female ticks which were fed with infected blood but no Bartonella DNA was amplified from the larvae eclosed from those eggs [14].

\section{Conclusions}

In summary, this case study shows prevalence of Bartonella spp. in a cat and their ectoparasites (ticks). The circulation of $B$. henselae is maintained by ectoparasites and animals. A lot more research has to be done to elucidate the role of ticks in the transmission of $B$. henselae to estimate the risk of infection to humans and pets.

\section{Additional files}

Additional file 1: Figure S1. Alignment 16S rDNA. (DOCX 14 kb) Additional file 2: Figure S2. Alignment 16S-23S-ITS. (DOCX 14 kb)

\section{Abbreviations}

badA: Bartonella adhesin A gene; Bep: Bartonella effector protein; DNA: Deoxyribonucleic acid; IgG: Immunoglobulin g; IIFA: Indirect immunofluorescence assay; ITS: Internal transcribed spacer; PCR: Polymerase chain reaction; virB: VirBNirD4 type IV secretion system gene

\section{Acknowledgements}

The authors thank Corinna Illich, Carmen Jung, Rebecca Kaufmann, Heike Podlich, Claudia Stolz and Yael Wiegand for excellent technical assistance. This paper has been sponsored by Bayer Animal Health in the framework of the 12th CVBD World Forum Symposium.

\section{Funding}

This work was partially supported by a grant from the Bayer Animal Health Company, Leverkusen, Germany and by the Robert Koch-Institute, Berlin, Germany (Bartonella consiliary laboratory, 1369-354). Funding parties had no influence on data analysis, data interpretation, or writing of the manuscript.

\section{Availability of data and materials}

The data supporting the conclusions of this article are included within the article.

\section{Authors' contributions}

YR performed cat patient care, YR and WB performed diagnostics and experiments, YR and VK planned the study and wrote the paper. All authors read and approved the final manuscript.

\section{Competing interests}

The authors declare that they have no competing interests.

Consent for publication

Not applicable. 


\section{Ethics approval}

VK holds a permit of the state veterinary board of Hesse/Germany allowing to analyze animal samples for medical reasons to detect Bartonella infections. Blood was taken for medical reasons.

\section{Received: 17 December 2016 Accepted: 17 February 2017} Published online: 13 March 2017

\section{References}

1. Versalovic J, Jorgensen JH, Funke G, Warnock DW, Landry ML, Carroll KC. Manual of clinical microbiology. 10th ed. Washington DC: American Society for Microbiology; 2011.

2. Rolain JM, La Scola B, Liang Z, Davoust B, Raoult D. Immunofluorescent detection of intraerythrocytic Bartonella henselae in naturally infected cats. J Clin Microbiol. 2001;39:2978-80.

3. Kordick DL, Brown TT, Shin K, Breitschwerdt EB. Clinical and pathologic evaluation of chronic Bartonella henselae or Bartonella clarridgeiae infection in cats. J Clin Microbiol. 1999;37:1536-47.

4. Chomel BB, Wey AC, Kasten RW, Stacy BA, Labelle P. Fatal case of endocarditis associated with Bartonella henselae type I infection in a domestic cat. J Clin Micorbiol. 2003;41:5337-9

5. Breitschwerdt EB, Broadhurst JJ, Cherry NA. Bartonella henselae as a cause of acute-onset febrile illness in cats. JFMS Open Reports. 2015;1(2). doi:10.1177/ 2055116915600454.

6. Bergh K, Bevanger L, Hanssen I, Loseth K. Low prevalence of Bartonella henselae infections in Norwegian domestic and feral cats. Acta Pathol Microbiol Immunol Scand. 2002;110:309-14.

7. Solano-Gallego L, Hegarty B, Espada Y, Llull J, Breitschwerdt E. Serological and molecular evidence of exposure to arthropod-borne organisms in cats from northeastern Spain. Vet Microbiol. 2006;118:274-7.

8. Relman DA, Loutit JS, Schmidt TM, Falkow S, Tompkins LS. The agent of bacillary angiomatosis. An approach to the identification of uncultured pathogens. N Engl J Med. 1990;323:1573-80.

9. La Perkocha, Geaghan SM, Yen TS, Nishimura SL, Chan SP, Garcia-Kennedy $\mathrm{R}$, et al. Clinical and pathological features of bacillary peliosis hepatis in association with human immunodeficiency virus infection. N Engl J Med. 1990:323:1581-6.

10. Foil L, Andress E, Freeland RL, Roy AF, Rutledge R, Triche PC, et al. Experimental infection of domestic cats with Bartonella henselae by inoculation of Ctenocephalides felis (Siphonaptera: Pulicidae) feces. J Med Entomol. 1998:35:625-8.

11. Billeter SA, Levy MG, Chomel BB, Breitschwerdt EB. Vector transmission of Bartonella species with emphasis on the potential for tick transmission. Med Vet Entomol. 2008;22:1-15.

12. Sormunen JJ, Penttinen R, Klemola T, Hanninen J, Vuorinen I, Laaksonen M, et al. Tick-borne bacterial pathogens in southwestern Finland. Parasit Vectors. 2016;9:168.

13. Schouls LM, van de Pol I, Rijpkema SG, Schot CS. Detection and identification of Ehrlichia, Borrelia burgdorferi sensu lato, and Bartonella species in Dutch Ixodes ricinus ticks. J Clin Microbiol. 1999;37:2215-22.

14. Cotté V, Bonnet S, Le Rhun D, Le Naour E, Chauvin A, Boulouis H-J, et al. Transmission of Bartonella henselae by Ixodes ricinus. Emerg Infect Dis. 2008;14:1074-80.

15. Reis C, Cote M, Le Rhun D, Lecuelle B, Levin ML, Vayssier-Taussat M, et al. Vector competence of the tick Ixodes ricinus for transmission of Bartonella birtlesii. PLoS Negl Trop Dis. 2011:5:e1186.

16. Telford SR, Wormser GP. Bartonella spp. transmission by ticks not established. Emerg Infect Dis. 2010;16:379-84.

17. Arthur D. British ticks. London: Butterworths; 1963.

18. Riess T, Dietrich F, Schmidt KV, Kaiser PO, Schwarz H, Schafer A, et al. Analysis of a novel insect cell culture medium-based growth medium for Bartonella species. Appl Environ Microbiol. 2008;74:5224-7.

19. Dauga C, Miras I, Grimont PA. Identification of Bartonella henselae and B. quintana 16s rDNA sequences by branch-, genus- and species-specific amplification. J Med Microbiol. 1996;45:192-9.

20. Dietrich F, Schmidgen T, Maggi RG, Richter D, Matuschka F-R, Vonthein R, et al. Prevalence of Bartonella henselae and Borrelia burgdorferi sensu lato DNA in Ixodes ricinus ticks in Europe. Appl Environ Microbiol. 2010;76:1395-8.

21. Cherry NA, Maggi RG, Cannedy AL, Breitschwerdt EB. PCR detection of Bartonella bovis and Bartonella henselae in the blood of beef cattle. Vet Microbiol. 2009;135:308-12.
22. Glaus T, Hofmann-Lehmann R, Greene C, Glaus B, Wolfensberger C, Lutz H. Seroprevalence of Bartonella henselae infection and correlation with disease status in cats in Switzerland. J Clin Microbiol. 1997;35:2883-5.

23. Carrade DD, Foley JE, Borjesson DL, Sykes JE. Canine granulocytic anaplasmosis: a review. J Vet Intern Med. 2009;23:1129-41.

24. Riess T, Andersson SG, Lupas A, Schaller M, Schafer A, Kyme P, et al. Bartonella adhesin a mediates a proangiogenic host cell response. J Exp Med. 2004;200:1267-78.

25. Schülein R, Dehio C. The VirB/VirD4 type IV secretion system of Bartonella is essential for establishing intraerythrocytic infection. Mol Microbiol. 2002:46:1053-67.

26. Schmid MC, Schülein R, Dehio M, Denecker G, Carena I, Dehio C. The VirB type IV secretion system of Bartonella henselae mediates invasion, proinflammatory activation and antiapoptotic protection of endothelial cells. Mol Microbiol. 2004:52:81-92.

27. Koesling J, Aebischer T, Falch C, Schülein R, Dehio C. Cutting edge: antibodymediated cessation of hemotropic infection by the intraerythrocytic mouse pathogen Bartonella grahamii. J Immunol. 2001;167:11-4

28. Abbott RC, Chomel BB, Kasten RW, Floyd-Hawkins KA, Kikuchi Y, Koehler JE, et al. Experimental and natural infection with Bartonella henselae in domestic cats. Comp Immunol Microbiol Infect Dis. 1997;20:41-51.

29. Okujava R, Guye P, Lu YY, Mistl C, Polus F, Vayssier-Taussat M, et al. A translocated effector required for Bartonelladissemination from derma to blood safeguards migratory host cells from damage by co-translocated effectors. PLoS Pathog. 2014;10(6):e1004187.

30. Rynkiewicz EC, Hemmerich C, Rusch DB, Fuqua C, Clay K. Concordance of bacterial communities of two tick species and blood of their shared rodent host. Mol Ecol. 2015:24:2566-79.

\section{Submit your next manuscript to BioMed Central and we will help you at every step:}

- We accept pre-submission inquiries

- Our selector tool helps you to find the most relevant journal

- We provide round the clock customer support

- Convenient online submission

- Thorough peer review

- Inclusion in PubMed and all major indexing services

- Maximum visibility for your research

Submit your manuscript at www.biomedcentral.com/submit
C) BioMed Central 